\title{
Countermeasures of Libraries in Colleges and Universities after Epidemic Situation
}

\author{
Haoran Tian \\ Ji Lin Justice Officer Academy, Changchun 130062, Jilin, China.
}

\begin{abstract}
The outbreak of corona virus pneumonia has brought about a great impact on social production and life. Libraries in colleges and universities need to adjust in time to cope with the epidemic. How to effectively play the role of libraries has an important impact on the development of education in tertiary institutions. This paper mainly introduces the impact of the epidemic situation on library work, analyzes the working principles of the library under the epidemic situation in colleges and universities, and explores the countermeasures of the library under the epidemic situation, so as to provide some ideas for guiding the effective library work after the epidemic.
\end{abstract}

Keywords: Colleges and Universities; Epidemic Situation; Library; Response

Affected by the epidemic situation, colleges and universities in the first half of 2020 almost did not start normal school. At present, the epidemic situation has developed to the post epidemic era, the domestic epidemic situation has not completely ended, and the epidemic situation in many foreign countries is still in the state of outbreak. Based on this, the libraries of colleges and universities, as the public places and densely populated places of schools, should still be alert to the epidemic situation and do a good job in prevention and control. To maintain the normal management and service order, colleges and universities should do a good job in the prevention and control of the epidemic to the maximum extent, and ensure the safety education and learning of teachers and students in school. Therefore, the relevant colleges and universities need to take active measures should be taken by relevant colleges and universities for related work in library in the post epidemic era.

\section{The impact of epidemic situation on Library work}

Before the outbreak of the epidemic, the work of university libraries was basically the same as that of other university libraries. Students and teachers studied in the library, looked for learning materials they needed, and went to self-study. Library people come and go every day. In some study rooms and borrowing rooms, a large number of people shuttle back and forth, and the flow of people is relatively large. Affected by the epidemic situation, the library also needs to do a good job of targeted epidemic prevention and control measures. First of all, the implementation of comprehensive disinfection in the library, the relatively strong circulation of books and materials for timely disinfection, inspection and management should be carried out. It is necessary to check the health code of the entry personnel to ensure the safety of the area and avoid hidden dangers. And the basic body temperature test, symptom observation, etc. are carried out to ensure that there is no fever, cough, fatigue, or mental disorder among the people entering the library. It is necessary to keep the staff on duty during the opening time, increase the participation of volunteers in the management to assist the librarians in checking, killing, borrowing and returning. Building a comprehensive and systematic epidemic prevention, control and management system has brought certain challenges to library management and service.

Copyright (C) 2020 Haoran Tian

doi: 10.18282/le.v9i7.1524

This is an open-access article distributed under the terms of the Creative Commons Attribution Non-Commercial License

(http://creativecommons.org/licenses/by-nc/4.0/), which permits unrestricted non-commercial use, distribution, and reproduction in any medium, provided the original work is properly cited. 


\section{Principles of library work under the epidemic situation in colleges and universities}

First, wear masks, line up at the "entrance" of the hall on the first floor of the library, with a distance of 1 meter, and show the relevant certificates such as the borrowing card. Only when the body temperature is normal can you enter the library.

Second, after entering the hall, you can enter the library, periodical room and study room.

Third, during the epidemic period, the library encouraged students to book online booking;

Fourth, one table for each person in the periodical room, newspapers and periodicals are not allowed to borrow;

Fifthly, the study room is pasted with the sign of "study place". Please take seat according to the sign;

Sixth, please take the" exit" when leave the library.

Seventh, take safety as the premise, and ensure that the library can play its due role in the teaching service;

Eighth, with innovation as the goal, through the application of effective technology and intelligent equipment, the innovation level of library service, the ability of interlibrary loan and resource sharing can be continuously improved to promote the construction and development of smart library.

\section{Countermeasures of libraries in colleges and universities after the epidemic situation}

At this stage, China has entered a period of relatively stable epidemic situation, and relevant colleges and universities have begun to gradually resume normal teaching work. University libraries are also open to teachers and students. Based on the needs of national epidemic prevention and control, university libraries need to further do a good job in epidemic prevention and control work, cooperate with schools for prevention and measures work in epidemic, in order to ensure the safety and health of school staff, do not give the opportunity of epidemic spread, and make a little contribution to the national epidemic prevention and control work.

\subsection{Strengthening publicity and keeping all staff alert}

Although the control effect of coronavirus epidemic situation in China is remarkable, once the epidemic occurs again, the harm and loss caused by it will be huge, and it will also seriously threaten people's life safety. The coronavirus pneumonia is still in progress. We must maintain public vigilance against the epidemic, start from the individual, and fight for the epidemic. In this regard, colleges and universities should actively respond to the needs of epidemic prevention and control, strengthen the cultivation of awareness of epidemic prevention and control for teachers and students, so that we cannot relax and do a good job in self-protection.

In view of the epidemic prevention and control work in the post epidemic era, the libraries of colleges and universities should strengthen publicity and improve the awareness of protection. We should do a good job in the propaganda of how to prevent and control the epidemic situation and prohibit the spread of the disease through library propaganda column, publicity bulletin board, electronic screen, WeChat official account, and timely publicizing health knowledge of coronavirus prevention and control by means of posting publicity materials, playing rolling videos, hanging banners, issuing WeChat official account information, etc, so as to enhance self-protection consciousness of teachers and students and related personnel in school.

\subsection{Doing a good job in the germicidal action and eliminating potential safety hazards}

In order to further strengthen the overall arrangement and responsibility implementation of the epidemic prevention and control work, and pay close attention to the preparation work before students return to school, the libraries of colleges and universities should organize all librarians at the hall of Aizhi at the first floor to hold the deployment meeting of students returning to school during the period of epidemic prevention and control in accordance with the requirements of school epidemic prevention and control work. According to the school prevention and control work guide, combined with the actual work of the library, librarians should be organized to formulate and learn the "library entry instructions during epidemic prevention and control". It is emphasized that the library is an important 
public place of the school, which is necessary to do a good job in the supervision and management of the steps such as wearing masks before entering the library, measuring the body temperature and registering the entry certificate. Strict implementation of the school epidemic prevention and control discipline, the station, accurate prevention and control can be improved. The director of the library should make overall planning and careful deployment, conduct a comprehensive inspection of all public facilities in the library, and organize all librarians to carry out bookshelf sorting, cleaning, and killing in the library.

\subsection{Improving online service and reducing personnel flow and contact}

At present, the construction of smart library has been implemented in many colleges and universities. In view of the needs of the prevention and control of the epidemic, the university library should speed up the construction of digital service resources, actively carry out online service business, and build online library resource database. By actively carrying out online services and innovating service methods, we can enrich the cultural life of teachers, students and readers during the epidemic prevention and control period. The library should pool ideas and take the initiative to innovate. By using the library's website, wechat public platform and Goethe's borrowing machine, the library should actively carry out "epidemic knowledge I know" breakthrough answer questions, and recommend good books online and offline to carry out reading promotion activities. Readers can also access digital resources such as online e-books, audio listening books, daily news updates, digital exhibitions and other digital resources on the webpage, Wechat public platform and Goethe's borrowing machine, so as to change offline to online, break the space limitation, and achieve barrier free reading for "book anti epidemic".

The improvement of library online service is also the need to promote the concept of lifelong learning, which is conducive to students to develop the habit of using fragmented time to learn, making learning easy, anytime, anywhere. Where there is network coverage, there is reading; where there are people, there is the flow of knowledge and information.

\subsection{Doing a good job in the security inspection of library entry and reporting the abnormal situation in time}

In the post epidemic era, in order to meet the needs of different students for library services, it is necessary not only to open online library services, but also to further improve offline related services. Combined with the actual needs of library work, comprehensive safety and health inspection should be carried out for the entry personnel.

The first is to measure the body temperature. Intelligent temperature detection is carried out for every person entering the library. The personnel with high body temperature are forbidden to enter the library.

Secondly, all visitors need to wear masks. Those who do not wear masks are not allowed to enter.

Check the Ankang code. The entry personnel need to scan the Ankang code on site. The green code can be used.

Symptom observation: the inspectors need to observe the symptoms of the staff entering the library and check whether the relevant personnel have cough, fatigue and other symptoms. If so, they are not allowed to enter the library.

For those with severe symptoms, especially those with fever, they should report to the school in time, and require students to check at the designated place. If necessary, nucleic acid examination should be carried out to prevent the disease. For those who have some suspected symptoms, the library should isolate them in time to avoid contact with other people outside, just in case.

\section{Conclusion}

In the post epidemic era, the prevention and control of epidemic situation is still one of the key tasks of educational institutions, which cannot be taken lightly. At present, some libraries in colleges and universities are slack in epidemic prevention and control, and the related work is not rigorous, which is not conducive to the protection of the safety and health of school staff, as well as the implementation of epidemic prevention and control work. The library work in colleges and universities needs to be adjusted in time, focusing on library resource services and epidemic prevention and control, and taking relevant measures to ensure the safe and effective development of library work under the new epidemic situation, and play a positive role in the education of college students. 


\section{References}

1. Liu B, Chao S, Wang J. Emergency Information Service System of Professional Libraries for Public Health Emergencies--A Case Study of the National Library of Medicine. Journal of the National Library of China,2020,29(05):77-90.

2. Wu L.Practice of University Library Service Guarantee and Reading Promotion under the Background of Major Public Health Events--Taking the Library of Guizhou University of Traditional Chinese Medicine as an Example. Inside and Outside Lantai,2020(27):77-78.

3. Chu Y, Jiang Y, Zuo L. Research on the Innovation of University Library Reading Promotion in Public Emergencies, Journal of University Library2020,38(05):20-25. 